\title{
The Look of the Devil: Multiple Cranial Neuropathies
}

\author{
Alla A. Vein \\ Department of Neurology, Leiden University Medical Center, Leiden, The Netherlands
}

\section{Keywords}

Strabismus · Art · Devil's image

\begin{abstract}
The sculpture of the devil on a portal of the Lichtenthal Abbey School in Baden-Baden, Germany displays neurological pathology, possibly consistent with multiple cranial neuropathy. One of the main abnormalities is an exotropia strabismus, a feature rarely depicted in works of art portraying the devil.

(c) 2017 S. Karger AG, Basel
\end{abstract}

\section{Introduction}

When a medical doctor studies works of art, he cannot help but notice physical abnormalities, which the general public probably would not recognize. The first features one pays attention to are the eyes and the facial expression. A face depicted on a portal of the school building of the Lichtenthal Abbey in Baden-Baden, Germany, made me stop and look closely. It fascinated me. I wondered about what it symbolized and so I enquired about the history of the building and the sculpture, also out of neurological curiosity. Based on the scarce information gained, I will speculate on the possible "etiological" background of the sculpture.

\section{KARGER}

(๑) 2017 S. Karger AG, Basel

E-Mail karger@karger.com

www.karger.com/ene

\section{The Building}

Although the history of the Lichtenthal Abbey dates back to 1245, the school building, where this particular sculpture was placed, was erected much later. The first school building in the grounds of the abbey was opened on February 9, 1815. Twenty years later, the Grand Duke of Baden requested that it should provide accommodation for an orphanage, forcing the school to move to an adjacent building, a former convent hospital. In 1877, the school was opened to girls of all denominations. As the number of pupils increased considerably, reconstruction was necessary. The abbey was allowed to carry out redevelopment. The new school, rebuilt in Jugendstil style (senior foreman of reconstruction - Hemberger, architect - Isenmann), with the sculpture on its façade, was opened in 1909 [1].

\section{The Sculpture}

The nuns of the abbey explained to me that the sculpture depicts the devil; above him, an angel rises who is embracing a little girl. The sculpture symbolizes the angel's victory over the demon (Fig. 1). It is not surprising that the sculpture depicts a girl because the school was still for girls only. For obvious reasons, my description will be exclusively of the static image, as functional tests were out of the

Alla A. Vein 


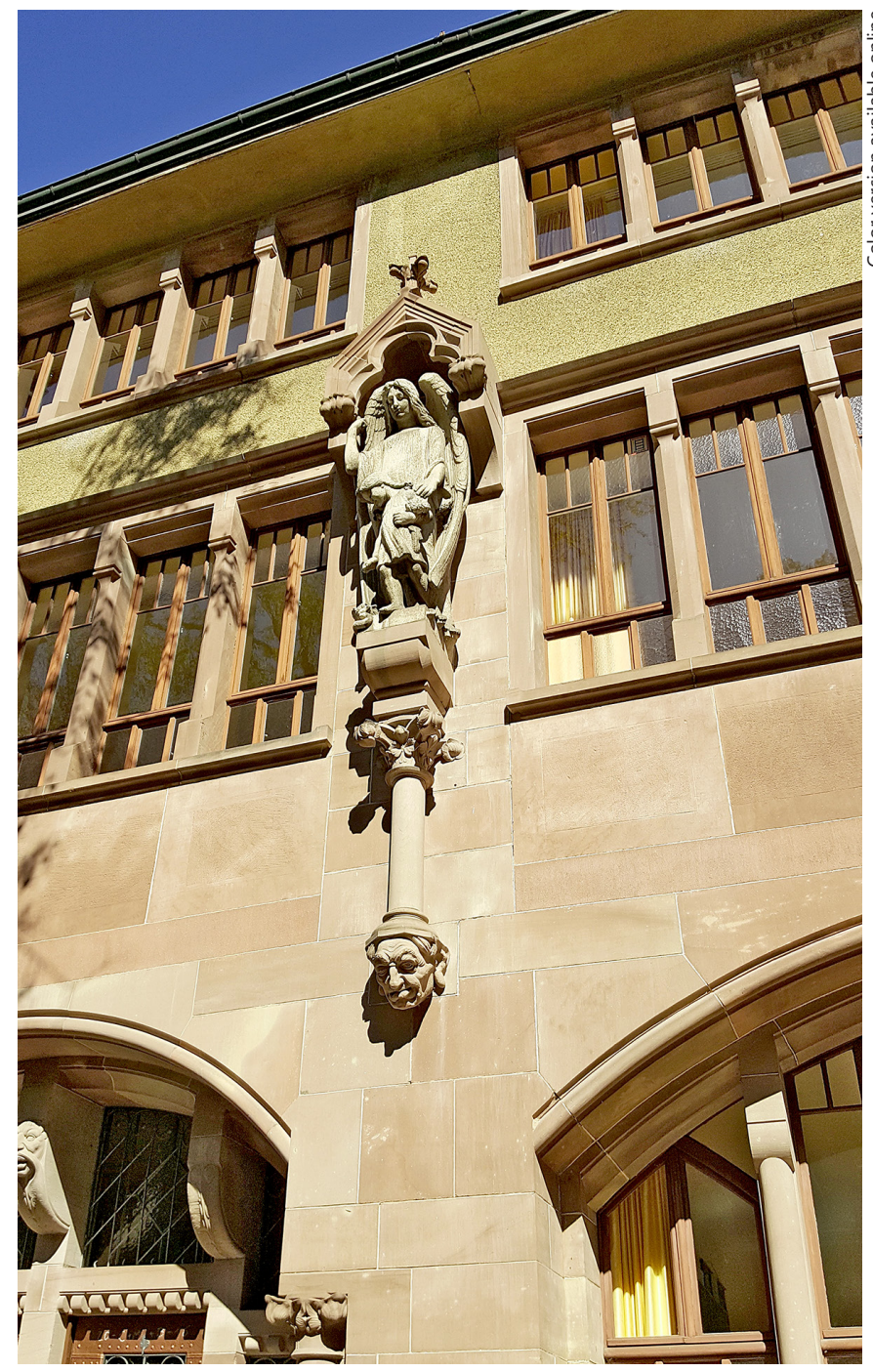

Fig. 1. The sculpture symbolizing the angel's victory over the demon on a portal of the Lichtenthal Abbey School in Baden-Baden, Germany.

question (Fig. 2). Theoretically, one can assume that the gaze of the devil is voluntarily directed upwards and to the left. As it is impossible, however, either to confirm or deny this option, I have chosen not to take it into consideration.

The main abnormality that attracted my attention was a particular form of strabismus: exotropia (divergent squint) with the right eye deviating outwards and a deviation of the left eye, whereby the visual axis of the left eye is higher than that of the right eye. Furthermore, there is a noticeable drooping of the right upper eyelid. On closer inspection, it would seem that the right corner of the mouth is lower and that there are fewer folds on the right forehead.

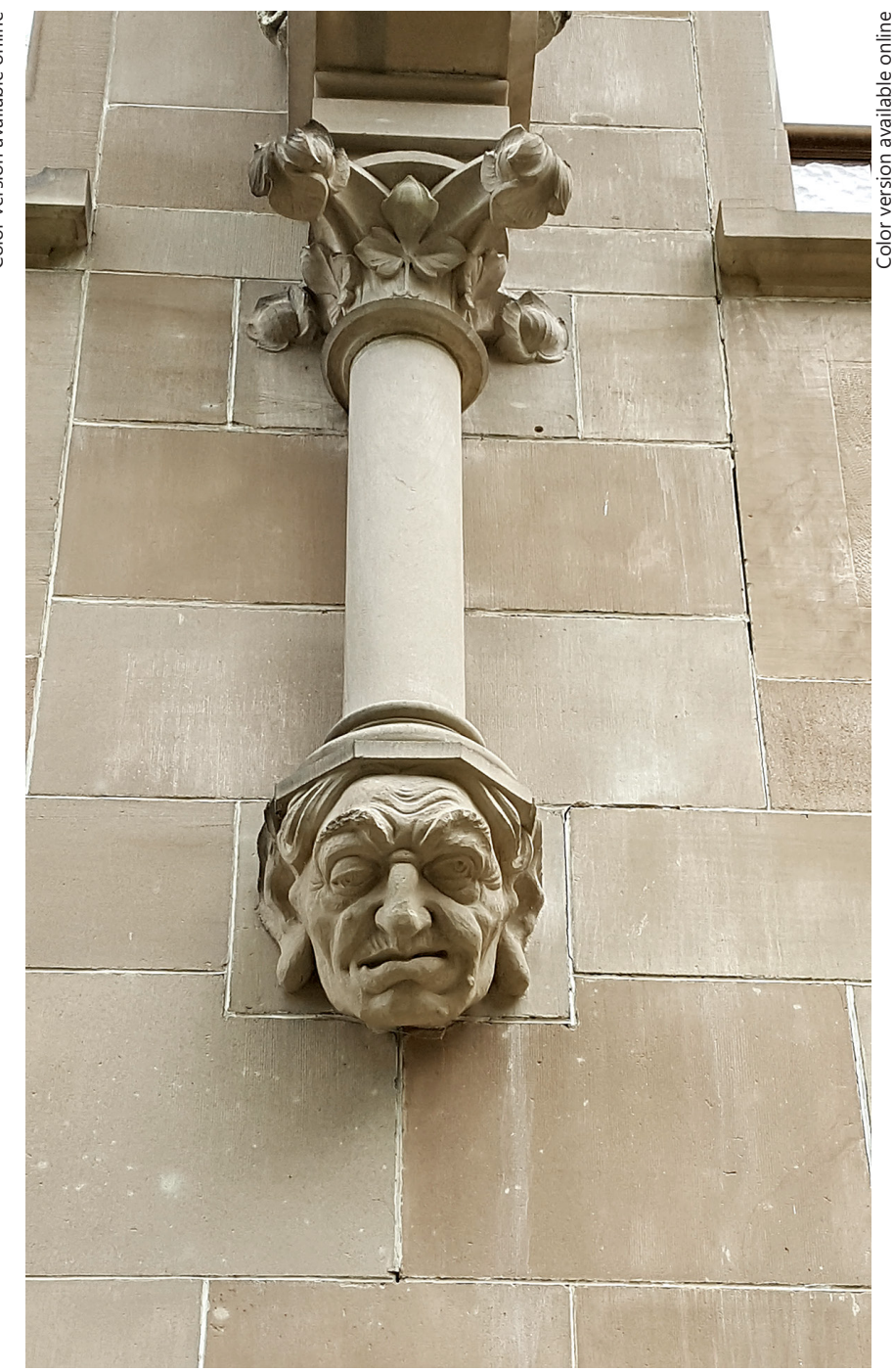

Fig. 2. The face of the devil. The Lichtenthal Abbey School, BadenBaden, Germany.

Accordingly, we might imply paresis of the following eye muscles: on the right side, levator palpebrae superior, medial rectus, superior rectus; on the left side, medial rectus, superior rectus and superior oblique. Among the facial muscles on the right, the most prominent is paresis of orbicularis ori; however, paresis of the frontal muscle would also seem plausible.

One might, therefore, suggest that we are dealing with a case of multiple cranial neuropathy $(\mathrm{MCN})$ with a double-sided pathology of the oculomotor nerve, possible pathology of the left trochlear nerve and facial palsy on the right side. 


\section{Multiple Cranial Neuropathies}

Gaze palsies, internuclear ophthalmoplegia and complex spontaneous eye movement abnormalities are often seen in brainstem lesions. Two main causes of MCN are known: (1) processes affecting multiple intramedullary structures of the brainstem; and (2) those affecting the extramedullary course of the cranial nerves. It is striking, especially for this historical retrospection, how the predominance of etiological causes has changed over the years. In the 19th century, when the classical brainstem syndromes were described and given eponyms, the most likely causes were tuberculosis and neurosyphilis, conditions seen much less nowadays. Currently, the most frequent causes of these syndromes are of vascular origin: infarctions and haemorrhages. Of course, there is also a whole spectrum of non-vascular disorders affecting the brainstem, such as demyelinating disease (multiple sclerosis, acute disseminated encephalomyelitis), vasculitides, neoplasms (gliomas, ependymomas), encephalitis (Bickerstaff s), central pontine myelinolysis and syringobulbia [2]. Most discussions of MCN etiology are found in case reports or small case series; very few large series have been reported. The largest to date was by Keane [3], who reviewed the findings of 979 cases of simultaneous or serial involvement of 2 or more different cranial nerves. According to this series, the abducens nerve was the most commonly involved cranial nerve, followed by the facial and the oculomotor nerve. Oculomotor and trochlear dysfunction was the most common combination of cranial nerve dysfunction, followed closely by trigeminal plus abducens, as well as trigeminal plus facial nerve palsies. The locations and causes were diverse, with cavernous sinus, brainstem and individual nerves being most frequently affected. Tumors were the most frequent cause (more than one-quarter of cases), followed by vascular disease, trauma, infection and the Guillain-Barré and Miller Fisher syndromes [3]. Sub-analysis of 578 cases of bilateral involvement of a single cranial nerve revealed the main causes to be trauma, infection, tumor, increased intracranial pressure, vascular disease and demyelination [4].

As the abbey is situated in the heart of the Black Forest (Schwarzwald) in Germany, Lyme disease is another option. This infection has been endemic in this particular region for a long time. Lyme disease is associated with an array of neurological complications involving both the peripheral and central nervous systems. However, the most cited pathology of cranial nerves in Lyme disease is facial nerve palsy; no involvement of the oculomotor nerve has been reported, except for a single case of orbital myositis [5].

The Look of the Devil: Multiple Cranial Neuropathies

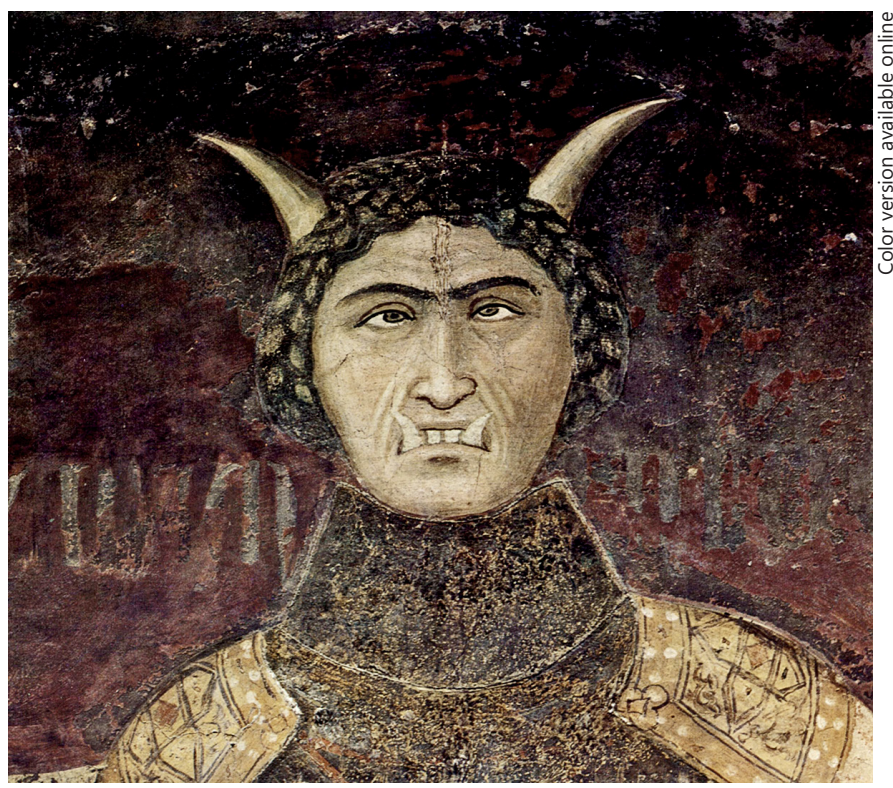

Fig. 3. The Tyrant in "Allegory of Bad Government". Ambrogio Lorenzetti (1338-1340).

\section{Strabismus in Art}

Images of strabismus in works of art are not rare. One may come across both forms of strabismus: esoand exotropia. There are very famous examples of strabismus in images, which have nevertheless become icons of beauty: Mona Lisa of Leonardo da Vinci, Venus of Sandro Botticelli, David of Michelangelo [7, 8]. Divergent strabismus is depicted in several self-portraits of Albrecht Dürer and his mother, suggesting a hereditary cause [6]. Recently published work, based on an analysis of 24 self-portraits of Rembrandt, demonstrates the appearance of an exotropic posture [9]. There are many examples of artists depicting strabismus in their self-portraits, for example, Guercino, Wyrsch, Ligabue [10].

The history of the fine arts is littered with examples of the devil's terrifying look. An Internet search of the devil's image demonstrates both numerous individual works and entire collected series on this subject. When individual paintings and sculptures of the devil are analyzed, strabismus is lacking in the overwhelming majority. Even most gargoyles do not have a strabismus. For example, the devil of the famous centerpiece sculpture of the St. Michel Fountain in Paris by Francisque-Joseph Duret, called "The Archangel St. Michael wrestling with the devil," does not show a strabismus. I could only identify a few devil's images with evident strabismus. One of the most 
prominent among them is the work of the Italian painter of the Sienese school, Ambrogio Lorenzetti "Allegory of Bad Government" (1338-1340) (Fig. 3).

At the exhibition at Stanford's Cantor Art Center, "Sympathy for the Devil: Satan, Sin and the Underworld" (2014) 40 works from 500 years of artistic portrayals of the devil were presented. This was an extended retrospective of how artists have variously depicted the devil over the past 5 centuries. All sorts of images - a fanged, horned demon; an armored, Apollo-like army leader; and a tailor of Nazi uniforms - were presented [11]. Only one devil's image portrayed esotropia strabismus; the work of Louis Boulanger, "The Round of the Sabbath" (1828).
To conclude, one might argue that the devil's face, depicted in the Lichtenthal Abbey, has an obvious ocular pathology and may be of interest to both medical and art historians.

\section{Acknowledgement}

I would like to thank Dr. Joost Haan for his advice and review of this paper.

\section{Disclosure Statement}

The author declares no conflicts of interest to disclose.

\section{References}

1 Archive of the Lichtenthal Abbey.

-2 Carroll CG, Campbell WW: Multiple cranial neuropathies. Semin Neurol 2009;29: 53-65.

3 Keane JR: Multiple cranial nerve palsies: analysis of 979 cases. Arch Neurol 2005;62:17141717.

4 Keane JR: Bilateral involvement of a single cranial nerve: analysis of 578 cases. Neurology 2005;65:950-952.
Reik L Jr, Burgdorfer W, Donaldson JO: Neurologic abnormalities in Lyme disease without erythema chronicum migrans. Am J Med 1986;81:73-78.

6 Aronson JK, Ramachandran M: The diagnosis of art: Durer's squint - and Shakespeare's? J R Soc Med 2009:102:391-393.

Mims JL 3rd: History of medicine: ocular disorders of the mona lisa (strabismus) and other famous paintings in the louvre, paris. Binocul Vis Strabolog Q Simms Romano 2012;27:35-38.
8 Shaikh S, Leonard-Amodeo J: The deviating eyes of Michelangelo's David. J R Soc Med 2005;98:75-76.

9 Mondero NE, et al: Was Rembrandt Strabismic? Optom Vis Sci 2013;90:970-979.

10 Philippe Lanthony Ophthalmology: The Impact of Eye Diseases on Painters, ed 1. Kugler Publications (March 20, 2009).

11 Carey Dunne the Changing Face of Satan, From 1500 to Today. The Wall Street Journal (August 18, 2014). 